\title{
A Theoretical Analysis of the Effectiveness of Sports Flipped Class Teaching Based on Motor Skill Learning
}

\author{
Dongmei Chen (i) \\ Anhui Professional \& Technical Institute of Athletics, Hefei 230051, China \\ Correspondence should be addressed to Dongmei Chen; cdm181004@163.com
}

Received 21 November 2021; Revised 16 December 2021; Accepted 17 December 2021; Published 8 February 2022

Academic Editor: Tongguang $\mathrm{Ni}$

Copyright (c) 2022 Dongmei Chen. This is an open access article distributed under the Creative Commons Attribution License, which permits unrestricted use, distribution, and reproduction in any medium, provided the original work is properly cited.

\begin{abstract}
This article compares the characteristics and advantages of flipped sports classrooms with other disciplines and traditional sports classrooms, and analyzes the characteristics and advantages of flipped sports classrooms, using the method of experimental comparison and comparative analysis to sort out the characteristics of Flipped classes in the application of teaching practice. Adjusting the teaching process and structure, with sports skill teaching as the main line, can create conditions for the deepening and expansion of PE. Students are the main body in a flipped class, which confirms the teaching concept. With the advent of the Internet era, students can access the information network at any time and from any location to gain PE knowledge. To meet students' learning needs, teachers must interact with them more and grasp teaching feedback more quickly. To sort out and research flipped classroom teaching in physical education, compare the use of flipped classroom teaching in physical education to traditional PE teaching over time, and demonstrate that flipped classroom teaching in physical education should be based on sports skills teaching and the teaching process. Making the necessary adjustments can help students learn in a positive environment. Then it examines two levels of technology and operation implementation in order to provide theoretical support for Flipped classroom teaching and improve student learning efficiency.
\end{abstract}

\section{Introduction}

Due to the ever-increasing use of the Internet, the educational model has undergone significant changes [1]. Flipped classrooms are becoming more common as the Internet era progresses. Using information technology in the classroom can help improve teaching efficiency and promote educational reform. Physical education (PE) is an important part of college and university education, as it promotes students' physical and mental health. The use of Flipped classes in college and university PE can be beneficial $[2,3]$.

Physical education (PE) classes are becoming more templated in today's colleges and universities [4]. PE teachers plan all of their lessons meticulously, no matter where they are in the process. Students are doing teacher- directed preparation activities, learning physical skills, and not having enough room in their PE class for self-expression. [5] Inflexible and mechanical, with no room for play. If things keep going this way, things will only get worse. PE teachers use this teaching model to instill physical skills, create various training activities to help students improve their sports skills, and exaggerate students' athletic abilities [6]. This teaching model fails to effectively cultivate students' athletic and humanistic qualities, which has a negative impact on their personal development [7].

Teachers must test the theory in the real world to ensure that flipped sports classrooms are as effective as they claim to be. It is hoped that this study will encourage the use of flipped classroom teaching methods in physical education, thereby speeding up the reform of the subject [8]. 


\section{Related Work}

As a result of its widespread use in the classroom, it has evolved into a new teaching method that is in opposition to traditional teaching theories. Is it possible to describe a flipped class?

The Flipped Class education model was created by Jonathan Berman and Aaron Sams, two chemistry teachers at Rocky Mountain Woodland Park High School in Colorado, USA [9].

Flipped classes, according to the literature [10], are a method for increasing interactive and individualized contact time between teachers and students; they are a personalised teaching environment in which students can receive individualized education. The teacher is no longer the dictator on the podium, but the instructor of the students' learning; the teaching content is saved, and students can review it at any time based on their own circumstances; the teacher is no longer the dictator on the podium, but the instructor of the students' learning; the teaching content is saved, and students can review it at any time based on their own circumstances. It's a teaching method that combines direct explanation with constructivist learning to prevent students from falling behind in class.

Literature [11] believes that the role of teachers and students in traditional classroom teaching has been rearranged as a result of the Flipped Class, and that classroom time is better utilized by reversing the knowledge transfer and internalization arrangements.

To complete the knowledge transfer and enter the stage of knowledge internalization in a Flipped classroom, the literature [12] believes that knowledge transfer before class must exceed the teaching effect of teacher instillation. Students will not be able to do their best outside of the classroom if they do not do their best in class. To put it another way, the success of a lesson can be measured by the extent to which the students' prior learning has influenced the teacher's teaching in a traditional classroom and the students have fully internalized the course's content.

According to literature [13], students learn independently before class using teacher-created materials, then participate in teacher-student interaction activities and complete exercises in the classroom. [14].

According to literature [14], flipped classes involve teachers creating instructional videos that students watch at home or outside of class before returning to class to share their learning outcomes and experiences face-to-face.

The flipped classroom teaching model is a traditional teaching model in which students complete homework assignments at home, allowing them to learn at their own pace and in their own time, and the classroom becomes a place where teachers and students interact, promoting knowledge internalization through strategies such as solving doubts. [15] Literature.

According to Literature [16], flipped classrooms are located in an information-rich environment. Teachers use instructional videos as a primary mode of instruction for their students. Students watch and learn from videos before class. For both students and teachers, classes are a time for teaching and learning. Active communication and other forms of engagement are incorporated into a new approach to teaching and learning.

According to literature [17], a flipped class is an educational method that improves knowledge transfer and ability to retain it. As a result, he thinks Flipped Class should be renamed Flipped Teaching, because the relationship between teachers and students has fundamentally changed.

To summarize, this article's definition of flipped class is: Using information technology and network resource management as a platform, the teacher provides learning for students in class by creating teaching videos that allow students to complete knowledge learning before class and achieve the desired results. Exchange opportunities, assist students in internalizing knowledge, and create a new type of teaching model for students to become true masters of learning.

\section{Analysis of the Characteristics of Flipped Class}

3.1. Teaching Presupposition from Rigid Presupposition to Flexible Presupposition. The concept of Flipped class has more characteristics than the traditional classroom teaching mode, and it is also derived from the traditional classroom concept, and its characteristics are more prominent than the former [18].

In traditional classroom teaching, teachers have always held a dominant position in education, and students have always been in a passive learning state. In the Flipped Class Teaching model, the role attribute of classroom teaching is reversed. In the classroom, the student takes on the role of protagonist, while the teacher takes on the role of organizer.

Teachers in traditional classrooms have a tendency to meticulously design the curriculum, step by step, and gradually advance the pre-set mode [19]. The interlocking instructional design will not be able to move forward as long as the teacher decides what students are allowed to express. As a result, students are frequently given teachers' teaching tasks, and students lose more autonomy and critical thinking skills, as well as their enthusiasm for the classroom.

\subsection{The Teaching Process Is Reversed from First Teaching and} Then Learning to First Learning and Then Teaching. Teachers have traditionally imparted new knowledge to students in the classroom, while students work to retain it outside of class time. Internalization, on the other hand, is more challenging for students. The flipped classroom model can be fully integrated into student learning when used in the classroom. The use of a flipped classroom causes traditional teaching methods to be disrupted. It goes from teaching first and then educating to learning first and then educating, as shown in Figure 1.

Students use the network platform's resources to gain a basic understanding and knowledge of new information during their free time. Rather than teaching new information, the teacher uses class time to guide and explore students' previous learning problems. Internalization can then be enhanced, allowing students to gradually master higherlevel knowledge [20]. 


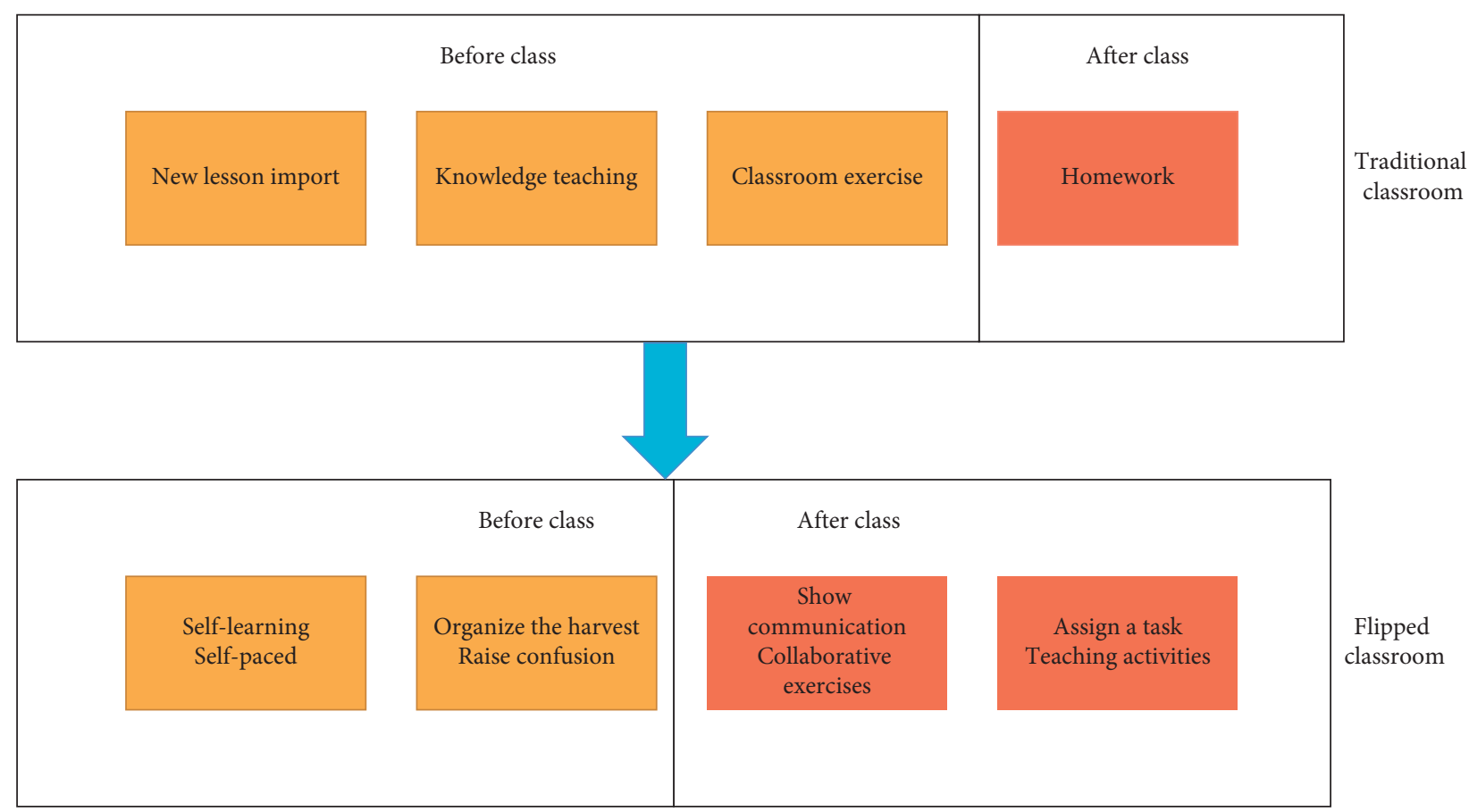

FIgURE 1: Process flip from traditional teaching to Flipped class.

3.3. Students' Learning Mentality Changes from Passive Acceptance to Active Exploration. In a traditional classroom, the teacher's lecture hall is the classroom. The students' task is to learn one line passively. Listening to the lesson and taking notes has become a routine for the students, and it is easy for them to lose interest in learning classroom knowledge. Flipped classrooms, as opposed to traditional classrooms, allow students to learn more actively, internalize concepts in class, and integrate them into their own cognitive structure. Students in the Flipped class spend more time in class discussing their own problems, interests, depth, value, and other issues in groups and with teachers, enhancing the value of classroom teaching and enabling each student to meet their own needs and increase interest, thereby enhancing the significance of Flipped class education in many ways.

\section{Necessary Conditions for the Implementation of Flipped Class}

4.1. Schools Must Have a Supporting Environment for Flipped Class. It is clear that information technology [21, 22] plays a critical role in implementing Flipped classes in the classroom; without it, Flipped classes will not be implemented. To some extent, information technology advancement is a precondition for using Flipped classes, and Flipped classes can only be presented with the help of highly developed information technology. As a result, since its inception in the nineteenth century, the Flipped class has only evolved [23]. This flipped teaching mode allows for self-study outside of class and classroom teaching after class. Technology is inextricably linked to any link, such as video production and transmission of teaching content, students watching video learning, and teacher-to-student individual communication. It is impossible to comprehend the situation and teach students according to their abilities without the use of information technology. A large classroom with cutting-edge technology is required for this flipped teaching mode.

The above-mentioned large environment of advanced information technology consists primarily of two major systems: hardware and software. Figure 2 depicts the four aspects of the hardware system:

4.2. The Overall Design of the School Curriculum. Flipped class implementation necessitates a thorough review of all courses offered at the school; otherwise, a slew of unfavorable implementation issues will arise. If each teacher makes partial or overall changes to the curriculum based on his or her own preferences, it will result in duplication of teaching content. Missed classes, subject confusion, and lengthy homework assignments after class are just a few of the issues. To avoid conflicts between courses, subjects, and time, general rules for overall design should be followed before implementing Flipped classes [24].

\subsection{School Teachers' Teaching Ability Requirements.} Before implementing a Flipped classroom, it is critical to address the issue of teachers' ability to use technology. Teachers in Flipped Classrooms should receive technical training from their schools. Teachers are the only ones who have truly mastered the use of information technology in education. With the help of network platforms, flipped classrooms can be implemented more efficiently [25].

Teachers' abilities are improving, so flipped classrooms cannot be ignored. To meet this demand, teachers of 


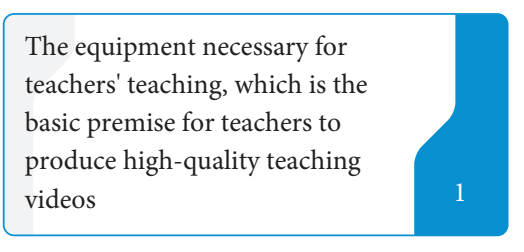

$$
\begin{aligned}
& \text { To ensure that the network is } \\
& \text { sufficiently smooth, to ensure } \\
& \text { the stability of video } \\
& \text { transmission and playback }
\end{aligned}
$$

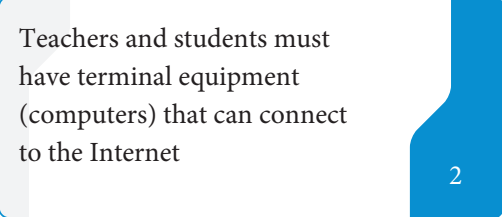

Sufficient memory for all service

equipment to ensure that

multiple functions can be

performed at the same time

FIgURE 2: The Flipped class hardware system covers four aspects.

physical education (PE) must meet higher standards. Because it differs so much from other academic disciplines, physical education (PE) instruction can be difficult to implement. Because there are so many students, PE teachers find it difficult to know when to use Flipped classes. PE teachers can make an informed decision based on their ability to manage a PE classroom and their extensive teaching experience. As a result, schools should focus on cultivating PE teachers' ability to teach in a variety of modes, including traditional indoor and outdoor teaching, as well as the Flipped classroom. Each method of instruction has its own set of benefits and drawbacks. They do not have a positive or negative aspect to them. Appropriate or inappropriate is the only way to tell them apart. In order to achieve the best learning effect, PE teachers should adjust measures to local conditions and time, according to specific teaching content, and the actual situation of students chooses the best teaching mode [26].

\section{Feasibility Analysis of Sports Flipped Class Teaching Based on Sports Skill Learning}

5.1. Acknowledgement of the Help of Flipped Class for Sports Learning. In a flipped class, students move from a traditional templated classroom to an autonomous-mutual aid classroom based on motor skills [27]. During this transition, students must move from passively imitating actions and passively following instructions to active learning [28]. As a result of the transformation of inquiry, communication, and learning, students must have the ability and awareness to learn sports skills independently, actively participate in teaching, and effectively interact with teachers. Through questionnaires, seminars, and other means, this paper investigates the role of sports skills on students' learning and independent learning of sports in six elective PE classes in a college class to assist in the teaching of sports skills, a total of 377 students, 195 boys and 182 girls. The state of one's motor skills is examined.

Sports skills can benefit students in the form of selfpaced learning before class, repeated observation after class to consolidate technical movements, and new ideas in movement arrangement in class. Figure 3 shows how students can learn sports skills by using open feedback.
As the Internet era and new learning methods have emerged, students' desire for sports resources has grown. Learning nowadays takes place outside of the classroom. When students have access to high-quality sports skills resources, they are more enthusiastic about sports. Learning physical education necessitates the acquisition of a wide range of abilities.

5.2. Investigation on the Flipped Class Consciousness of Autonomous Learning PE. The questionnaire survey is shown in Figure 4:

189 students prefer to study before class, especially if the number of views increases the day before class. After class, 135 students are still choosing to review. The majority of these students, according to interviews, are accustomed to the teacher's intuitive teaching in class, imitate the teacher, and spend less time reviewing after class. 57 students combined pre-class and post-class review. There are students who enjoy the course in particular, as well as students who lack coordination. Only a small percentage of students who prepare before class have poor self-study quality, according to survey and interview findings. Furthermore, many students continue to rely on their teachers' classroom instruction and do not take the initiative to do pre-class video learning, resulting in them remaining in class. Teachers and students are unable to communicate effectively with one another.

\subsection{The Teaching Concept of PE Teachers Needs to be Updated.} Thanks to technological advancements, PE reform in colleges and universities has gotten a big boost. Some PE teachers, who are eager to try out new ideas and methods, have embraced the use of information technology in PE. While this is a step forward, some PE teachers in traditional colleges and universities are still stuck teaching and improving sports skills as a coaching method. The teacherstudent relationship is marked by an unwillingness to study students' learning methods in depth and a lack of understanding of PE reform, rather than focusing on the development and improvement of students' self-directed learning abilities. The lack of themes and limited communication channels are to blame. It's common to focus on the students' 


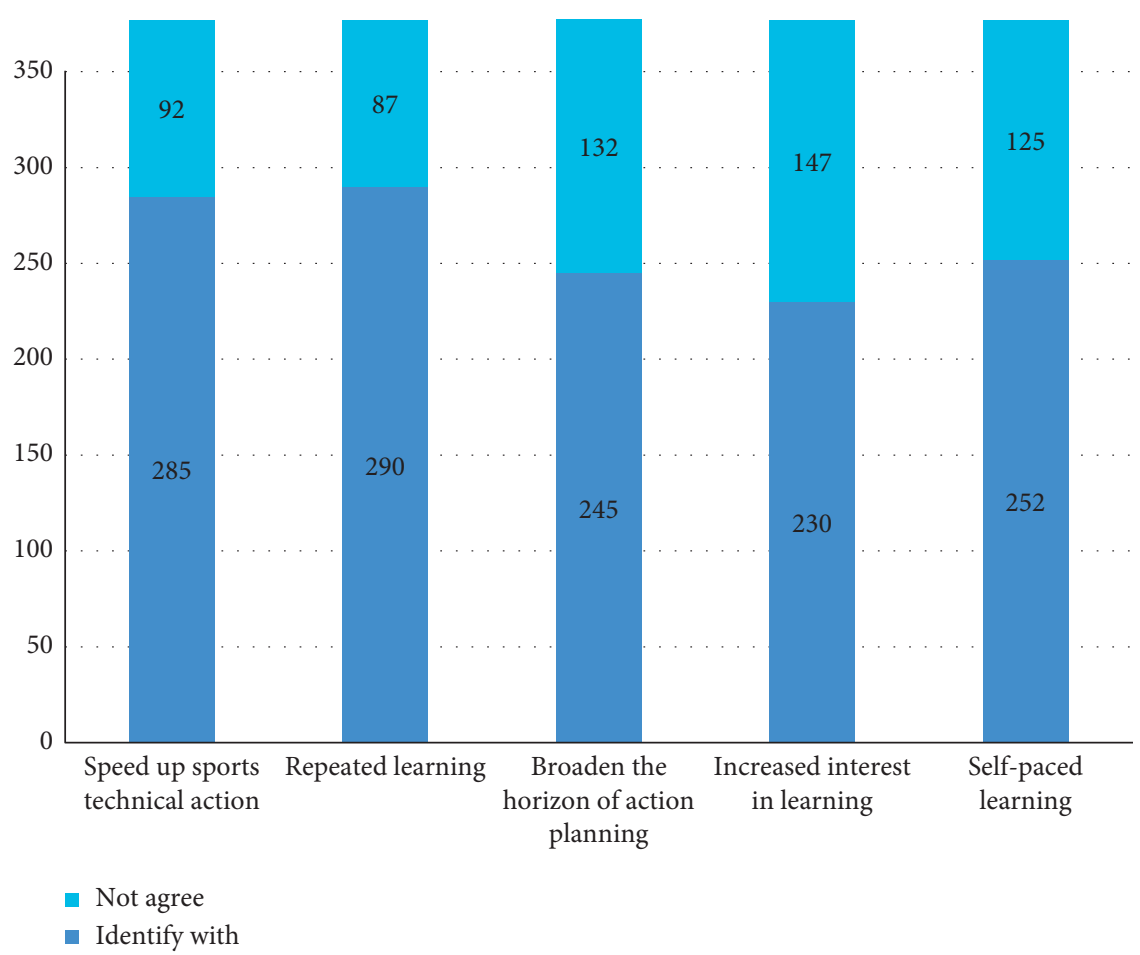

FIgURE 3: Statistics of Flipped classs for learning aids.

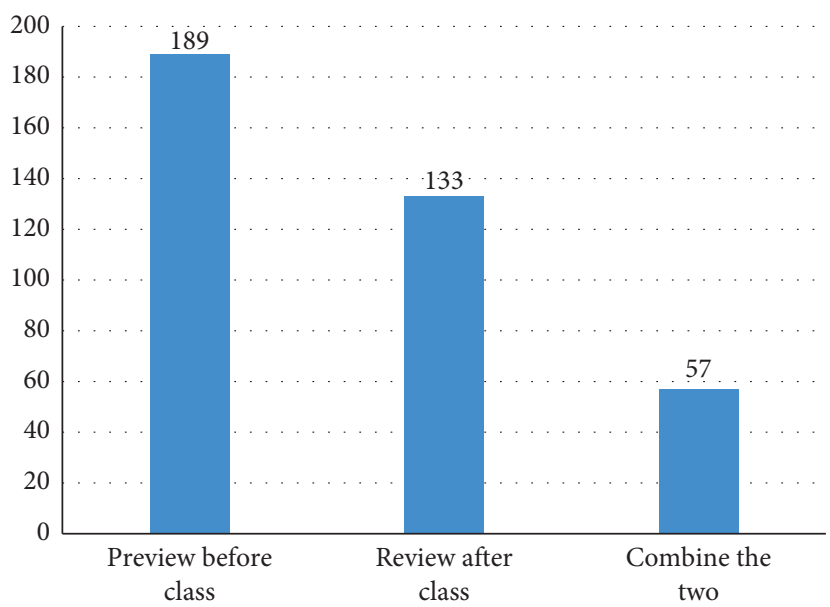

FIGURE 4: Survey statistics of self-learning sports Flipped class.

outcomes rather than their progress when evaluating their learning.

These sports departments have incorporated modern artificial intelligence [29-31] into their educational resources, making sports-related information more accessible to students, teachers, and the general public. In the field of physical education, the number of master's and doctoral students has steadily increased, as has the academic credentials of PE teachers hired by universities. In a flipped classroom, traditional PE is not taught. It has the potential to energize classrooms, motivate students to participate in sports, and improve the quality of classroom instruction, in addition to increasing student motivation and engagement in physical activity. In order to rely on the promotion of PE, college PE teachers must actively learn and implement the theories of Flipped Classrooms, as well as continually reflect on classroom issues and improve classroom teaching quality. Students' overall development and well-being.

For today's students, mobile phones can be the most direct means of instruction. Students can now access a wealth of sports-related information and video resources via their mobile phones and the Internet, and physical education teachers can use these tools to provide students with selfpaced, self-guided learning opportunities. It's all about resource sharing. PE instructors who believe in the practical and interactive nature of the curriculum and are unconcerned about the integration of technology into college PE courses are still in the minority. Flipped PE classes are 
difficult to develop because it is difficult for PE teachers who are used to a more traditional model of teaching to embrace the use of technology in their classrooms.

\section{Analysis on the Effectiveness of Sports Flipped Class Teaching Based on Motor Skill Learning}

What is the most effective method for teaching sports skills? To be an effective sports skill teacher, you must first understand what type of instruction is most effective. The term "effective" is used when students make specific progress or development after receiving instruction. To put it another way, the only way to tell if a teacher is effective is to look at their students' progress. Even if it is extremely difficult, teaching is ineffective or inefficient if the student does not want to learn or does not benefit greatly from it. Teachers use their own desire to learn as a starting point to pique students' interest in learning.

When it comes to classroom teaching and sports skill instruction, there are a lot of moving parts. This article uses University A and University B as examples. In A college PE, flipped classes are used, while in B college PE, traditional classes are used. There are 120 target classes, and no significant differences in physical fitness exist between them.

6.1. Comparative Analysis of Student Practice Density. Students in a flipped classroom learn sports knowledge and action methods through the use of micro-videos. In the micro-class learning stage, students begin to learn and practice knowledge and movement. As a result of this, students will be able to learn more about sports and movement methods, free up more time for students to practice activities, and increase the amount of effective practice time that they have available to them. The number of students practicing in the classroom increases. Flipped and traditional classrooms are compared in Table 1 by student practice density.

A reasonable range is shown in Table 1 for the practice density of the two pieces of information. Flipped Class A and traditional classrooms have very different student practice densities. Students in Flipped Class A have a higher practice density than students in traditional classrooms; however, students in Flipped Class B have a lower practice density than students in traditional classrooms. The experimental results show that $\mathrm{A}$ outperforms $\mathrm{B}$ in terms of autonomous learning ability. Open-motor skills are also more effectively taught using the Flipped Classroom model. A higher density of practice was achieved in traditional lessons as a result of teachers' use of course design methods that were more open to adopting the new curriculum concept than other teachers.

6.2. Comparative Analysis of Students' Practice Intensity. While physical exercise is the primary method for students to improve their overall physical fitness, they are also given more time for exercise, but with a limited amount of time to achieve an appropriate level of exertion. Students in both a traditional classroom and a flipped classroom work hard (heart rate) Table 2 shows the results of the comparative analysis.

Except for the squatting start, there are significant differences in exercise intensity between the Flipped classroom and the traditional classroom. When compared to traditional PE classes, Flipped PE classes require significantly more physical effort.

A passing class in basketball is shown in Figure 5 as an example of a rational analysis of exercise intensity.

The Flipped class's heart rates range from 120 to 150 beats per minute, which is between medium and low intensity and meets the basic requirements of warm-up activities, as evidenced by the gradual increase in heart rate over the first 12 minutes (preparatory activity). In the second half of the 15-36 minute part of the basic requirement, there are two peaks of 192 times/min and 204 times/min, but the duration is short, reflecting the quality exercises in the second half. It's undeniable. The heart rate gradually rises during the first 12 minutes of traditional classroom (preparatory activity), and it is between 126 and 144 beats per minute, which is medium to low intensity. It's finished as part of the warm-up. 15-30 minutes at 150 beats per minute in the first half, then 174 beats per minute in the second half. Despite this, the summit has yet to fall below its peak elevation. As evidenced by the rapid decline in intensity toward the end of the 33-40 minute period, the second half of the quality training arrangement lacked high-intensity quality training. Because the traditional classroom exercise load intensity is lower, students' physical fitness improves significantly when taught in a Flipped classroom.

6.3. Contrastive Analysis of Students' Mastery of Motor Skills. What impact will the flipped classroom have on motor skill acquisition? As shown in Table 3 of this article, two groups of experts, A and B, observe the students' on-the-spot mastery of motor skills and then grade them using a scale.

Micro-classes in the classroom teaching process and the organizational effects of the classroom are one of the most important factors that determine the level of skill mastery, especially for team Learning content with a lot of collaborative elements, as shown in a flipped class with strong team cooperation.

Unlike traditional teaching, flipped class teaching generates enthusiasm for sports participation, a reasonable amount of physical activity, and effective motor skill learning. Students' physical health and fitness have improved as a result of the Flipped classroom. In flipped classrooms, students are more encouraged to express themselves than in traditional classrooms. Through goal-led and task-driven micro-class and classroom learning, students are encouraged to actively participate in learning activities, deepen their autonomy, cooperation, and inquiry, and effectively change how they learn. Thanks to the flipped classroom, teaching methods are fundamentally altered, teachers create student-centered activities, and the concept of teaching for learning is realized. The ability to innovate has been significantly enhanced. 
TABLE 1: Comparison of student practice density between Flipped class and traditional classroom.

\begin{tabular}{|c|c|c|c|c|c|c|}
\hline \multirow{2}{*}{ Subject } & \multicolumn{2}{|c|}{ Flipped class } & \multicolumn{2}{|c|}{ Traditional classroom } & \multirow{2}{*}{$t$} & \multirow{2}{*}{$P$} \\
\hline & $\mathrm{n} 1$ & Proportion/\% & $\mathrm{n} 2$ & Proportion $/ \%$ & & \\
\hline Basketball pass & 46 & 75 & 45 & 51 & 2.367 & $<0.05$ \\
\hline Squat start & 49 & 79 & 47 & 39 & 3.966 & $<0.01$ \\
\hline $4 \times 50$ m Relay & 40 & 72 & 42 & 60 & 1.178 & $>0.05$ \\
\hline Aerobics & 44 & 73 & 43 & 59 & 1.342 & $>0.05$ \\
\hline
\end{tabular}

TABLE 2: Comparative analysis of student practice intensity between Flipped classs and traditional classrooms.

\begin{tabular}{|c|c|c|c|c|c|c|}
\hline \multirow{2}{*}{ Subject } & \multicolumn{2}{|c|}{ Flipped class } & \multicolumn{2}{|c|}{ Traditional classroom } & \multirow{2}{*}{$t$} & \multirow{2}{*}{$P$} \\
\hline & Average heart rate $\mathrm{X} 1$ & S1 & Average heart rate $\mathrm{X} 2$ & S2 & & \\
\hline Basketball pass & 135.31 & 19.01 & 126.50 & 18.85 & 2.427 & $<0.01$ \\
\hline Squat start & 123.63 & 17.11 & 119.56 & 16.32 & 1.284 & $>0.05$ \\
\hline $4 \times 50 \mathrm{~m}$ Relay & 145.51 & 30.24 & 130.53 & 23.52 & 2.992 & $<0.01$ \\
\hline Aerobics & 138.12 & 27.35 & 125.51 & 19.25 & 2.492 & $<0.01$ \\
\hline
\end{tabular}

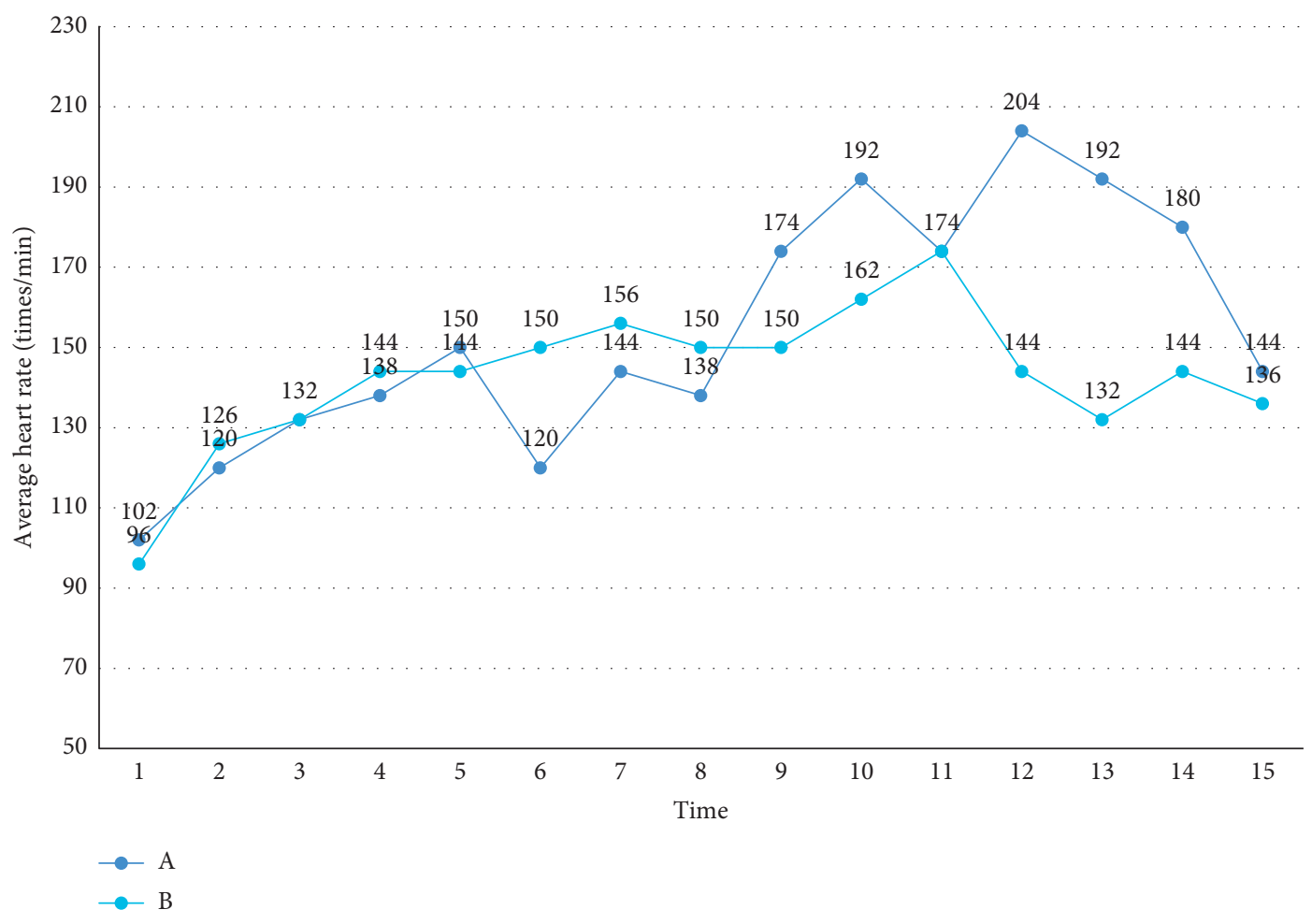

FIGURE 5: Comparison of heart rate curves between Basketball pass Flipped class and traditional classroom.

TABLE 3: Comparative analysis of students' motor skills mastery in Flipped classs and traditional classrooms.

\begin{tabular}{|c|c|c|c|c|}
\hline Subject & $\begin{array}{c}\text { Flipped class } \\
\text { Average mastery score }\end{array}$ & $\begin{array}{l}\text { Traditional classroom } \\
\text { Average mastery score }\end{array}$ & $t$ & $P$ \\
\hline Basketball pass & 92 & 62 & 3.420 & $<0.01$ \\
\hline Squat start & 86 & 74 & 1.517 & $>0.05$ \\
\hline $4 \times 50$ m Relay & 88 & 74 & 4.456 & $<0.01$ \\
\hline Aerobics & 53 & 51 & 0.259 & $>0.05$ \\
\hline
\end{tabular}




\section{Conclusions}

The popularity of flipped classroom teaching has grown as a result of the widespread use of multimedia technology. In order to stay on schedule, the college PE curriculum must be flipped to compensate for the information, content, and conceptual gaps. Maintain a steady pace with your field's current trends. The introduction of the flipped classroom teaching concept, which can serve as a supplement to, promotion of, and challenge to traditional university $\mathrm{PE}$ classroom teaching, could greatly benefit my country's colleges and universities. Some of the advantages of this method of teaching in college PE classrooms include a panoramic view of the content of PE courses, the development of sports interests and hobbies, and the establishment of good physical exercise habits. Traditional teaching methods and concepts have been reshaped by flipped classrooms for many teachers. Students and teachers are able to interact more frequently in a flipped classroom, resulting in a better value and emotional system for the students. In order to achieve a comprehensive assessment of students, we should evaluate their learning outcomes as well as their learning process using a comprehensive, multi-angle, and three-dimensional evaluation method.

Traditional teaching models influence Flipped class instruction; the network teaching environment is imperfect; there is a lack of relevant theoretical research and practical experience in sports practice Flipped classes; teachers lack production teaching resources and the ability to use microvideo; and students lack self-learning abilities.

\section{Data Availability}

The data used to support the findings of this study are included within the article.

\section{Conflicts of Interest}

The author does not have any possible conflicts of interest.

\section{Acknowledgments}

This study was supported by 2019 Anhui Province teaching quality engineering offline course (excellent offline open course) project (2019kfkc249); 2020 Anhui teaching quality engineering teaching demonstration course project.

\section{References}

[1] J. Ma, “Thinking of flipped class in PE," The Journal, vol. 5, pp. 67-70, 2021.

[2] T. Duan, "Research on the flipped class of PE in colleges and universities based on SPOC," Hubei Sports Science and Technology, vol. 37, no. 7, p. 4, 2018.

[3] J. Wang, "Research on teaching design of flipped class in college PE based on mobile learning," The Journal, vol. 4, pp. 51-56, 2021.

[4] $\mathrm{T}$. $\mathrm{Wu}$, "The teaching design of "the inclination angle and slope of a straight line" driven by context," Exam Weekly, vol. 000 , no. 23, p. 71, 2018.
[5] J. Yang, M. Shao, and L. Huang, "Application research of Flipped class based on micro-video resources in experimental teaching-_taking "Modern Educational Technology" experimental course as an example," The Journal, vol. 3, pp. 36-40, 2021.

[6] Y. Zhang, "Experimental research on the relationship between Flipped class teaching and motor skills acquisition," The Journal, vol. 10, pp. 144-147, 2021.

[7] D. Peng, "Research on the Flipped class teaching model based on MOOC-— taking college PE as an example," The Journal, vol. 10, pp. 142-145, 2021.

[8] L. Wang and Z. Duan, "The application of Flipped class based on micro-class in exercise physiology," Chinese Journal of Multimedia and Network Teaching, vol. 2, no. 2, pp. 16-17, 2019.

[9] C. Liu, D. Li, B. Zhang, and L. Li, "System evaluation and meta-analysis of the effectiveness of SPOC Flipped class teaching," The Journal, vol. 6, pp. 82-91, 2021.

[10] J. Tang and H. Cao, "Flipped class based on project learning: effectiveness and limits," The Journal, vol. 2, pp. 20-25, 2021.

[11] C. Liu, D. Li, B. Zhang, and Y. Ou, "System evaluation and meta-analysis of the effectiveness of SPOC Flipped class teaching," Open Education Research, vol. 25, no. 1, pp. 38+84-93, 2019.

[12] J. Zhang and G. Chen, "Research on the effectiveness of flipped class in PE courses," The Journal, vol. 17, p. 247, 2021.

[13] H. Zhong and L. Li, "Application of Flipped class based on micro-classes in college PE reform," The Journal, vol. 11, pp. 164-165, 2021.

[14] Y. Zhu, "Analysis of the value and implementation strategy of Flipped class in PE," The Journal, vol. 6, no. 22, pp. 73-74, 2021.

[15] J. Wang, "Practice and thinking on the application of Flipped class in exercise physiology," The Journal, vol. 8, no. 11, pp. 112-113, 2021.

[16] M. Zhou, "Feasibility analysis of "picture card style" gymnastics teaching model based on Flipped class," The Journal, vol. 9, no. 6, pp. 121-124, 2021.

[17] L. Hu and B. Zhang, "Flipped class and flipped learning: an analysis of the effectiveness of "flip," The Journal, vol. 4, no. 4, pp. 52-58, 2021.

[18] G. Wang, "The value and implementation strategy of Flipped class in PE," The Journal, vol. 12, no. 12, pp. 117-121, 2021.

[19] J. Huang, "New ideas for the reform of physiology teaching in higher vocational colleges based on the Flipped class," The Journal, vol. 3, pp. 37-39, 2021.

[20] G. Qi, "Research on foreign language learning anxiety under the flipped class mode," The Journal, vol. 5, no. 5, pp. 50-54, 2021.

[21] J. Zhang, Y. Liu, H. Liu, J. Wang, Y. Zhang, and B. Zh, "Distractor-aware visual tracking using hierarchical correlation filters adaptive selection," Applied Intelligence, pp. 1-19, 2021.

[22] M. Zhao, A. Jha, Q. Liu et al., "Faster Mean-shift: GPUaccelerated clustering for cosine embedding-based cell segmentation and tracking," Medical Image Analysis, vol. 7, Article ID 102048, 2021.

[23] G. Xia, J. Chen, J. Deng, and N. Xue, "Teaching practice and reflection on human physiology based on Flipped class," Education Modernization, vol. 33, no. 33, pp. 260-261, 2018.

[24] Y. Yao, "Modern educational technology based on moodle platform-a research on flipped class teaching," Modern Judaism, vol. 9, pp. 137-140, 2021. 
[25] B. Zhenbo, H. Pan, X. Tan et al., "Application research of Flipped class and hierarchical teaching methods in computer experiment teaching," The Journal, vol. 3, pp. 36-40, 2021.

[26] Y. Song, "The design of Flipped class teaching model in colleges and universities," The Journal, pp. 82-88, 2021.

[27] H. Zhang, Y. Li, and D. Bu, "A case study of the "Flipped class" teaching model for college physics experiments," Education Modernization, vol. 6, no. 6, pp. 147-148+161, 2020.

[28] Q. Liu, T. Xia, L. Cheng, M. Van Eijk, T. Ozcelebi, and Y. Mao, "Deep reinforcement learning for load-balancing aware network control in IoT edge systems," IEEE Transactions on Parallel and Distributed Systems, vol. 33, no. 6, pp. 1491-1502, 2021.

[29] M. Gao, R. Liu, and J. Mao, "Noise robustness low-rank learning algorithm for EEG signal classification," Frontiers in Neuroscience, vol. 1618, 2020.

[30] R. Liu, W. Cai, G. Li, X. Ning, and J. Yizhang, "Hybrid dilated convolution guided feature filtering and enhancement strategy for hyperspectral image classification," IEEE Geoscience and Remote Sensing Letters, vol. 19, 2021.

[31] X. Bai, X. Wang, X. Liu et al., "Explainable deep learning for efficient and robust pattern recognition: a survey of recent developments," Pattern Recognition, vol. 120, Article ID 108102, 2021. 